\title{
Complementation of Reduced Survival, Hypotension, and Renal Abnormalities in Angiotensinogen-deficient Mice by the Human Renin and Human Angiotensinogen Genes
}

\author{
Robin L. Davisson, ${ }^{*}$ Hyung-Suk Kim, ${ }^{\S}$ John H. Krege, ${ }^{\S} \mid$ Donna J. Lager, ${ }^{\ddagger}$ Oliver Smithies, ${ }^{\S}$ and Curt D. Sigmund ${ }^{\star}$ \\ *Department of Internal Medicine and Physiology and Biophysics, and ${ }^{\ddagger}$ Department of Pathology, The University of Iowa College of \\ Medicine, Iowa City, Iowa 52242; and ${ }^{\S}$ Department of Pathology, and $\|^{\|}$Department of Internal Medicine, The University of North \\ Carolina, Chapel Hill, North Carolina 27599
}

\section{Abstract}

The aim of this study was to determine whether elements of the human renin-angiotensin system (RAS) could functionally replace elements of the mouse RAS by complementing the reduced survival and renal abnormalities observed in mice carrying a gene-targeted deletion of the mouse angiotensinogen gene $(m A g t)$. Double transgenic mice containing the human renin (HREN) and human angiotensinogen (HAGT) genes were bred to mice heterozygous for the $\mathbf{m A g t}$ deletion and the compound heterozygotes were identified and intercrossed. The resulting progeny $(n=139)$ were genotyped at each locus and the population was stratified into two groups: the first containing both human transgenes $\left(\mathrm{RA}^{+}\right)$and the second containing zero or one, but not both human transgenes $\left(\mathrm{RA}^{-}\right)$. Despite appropriate Mendelian ratios of $\mathrm{RA}^{-}$mice that were wildtype $(+I+)$, heterozygous $(+I-)$, and homozygous $(-I-)$ for the deletion of $m A g t$ at birth, there was reduced survival of $\mathrm{RA}^{-} m A g t-I-$ mice to adulthood $\left(P<0.001\right.$ by $\left.\chi^{2}\right)$. In contrast, we observed appropriate Mendelian ratios of $\mathrm{RA}^{+} m A g t+l+, \mathrm{RA}^{+} m A g t+l-$, and $\mathrm{RA}^{+} m A g t-I-$ mice at birth and in adults $(P>0.05$ by $\left.\chi^{2}\right)$. These results demonstrate that the presence of both human transgenes rescues the postnatal lethality in $\mathrm{mAgt}-\mathrm{I}-$ mice. The renal histopathology exhibited by $\mathrm{RA}^{-} m A g t-I-$ mice, including thickened arterial walls, severe fibrosis, lymphocytic infiltration, and atrophied parenchyma, was also rescued in the $\mathrm{RA}^{+} m A g t-I-$ mice. Direct arterial blood pressure recordings in conscious freely moving mice revealed that $\mathrm{BP}$ (in $\mathrm{mmHg}$ ) varied proportionally to $\mathbf{m A g t}$ gene copy number in $\mathrm{RA}^{+}$mice $(\sim 20 \mathrm{mmHg}$ per $m A g t$ gene copy, $P<0.001)$. BP in $\mathrm{RA}^{+} m A g t-l-$ mice $(132 \pm 3, n=$ 14) was intermediate between wild-type $\left(\mathrm{RA}^{-} m A g t+I+\right.$, $105 \pm 2, n=9)$ and $\mathrm{RA}^{+} m A g t+I+(174 \pm 3, n=10)$ mice. These studies establish that the human renin and angiotensinogen genes can functionally replace the mouse angiotensinogen gene, and provides proof in principle that we can examine the regulation of elements of the human RAS and

Address correspondence to Curt D. Sigmund, Director, Transgenic Animal Facility, Departments of Internal Medicine and Physiology \& Biophysics, The University of Iowa College of Medicine, 6-432 Bowen Science Building, Iowa City, IA 52242. Phone: 319-335-7828; FAX: 319-335-7330; E-mail: curt-sigmund@uiowa.edu

Received for publication 29 October 1996 and accepted in revised form 26 December 1996.

J. Clin. Invest.

(C) The American Society for Clinical Investigation, Inc. 0021-9738/97/03/1258/07 \$2.00

Volume 99, Number 6, March 1997, 1258-1264 test the significance of human RAS gene variants by a combined transgenic and gene targeting approach. (J. Clin. Invest. 1997. 99:1258-1264.) Key words: genetics • transgenic animals $\bullet$ gene targeting $\bullet$ renin-angiotensin system $\bullet$ hypertension

\section{Introduction}

Human essential hypertension, or high blood pressure of undefined etiology, is an abnormality influenced by both polygenic and environmental factors. Compelling evidence in support of a genetic contribution to human essential hypertension stems from genetic epidemiology studies of twins and adopted siblings $(1,2)$. Technical advances in examining polygenic diseases in humans over the past few years has prompted numerous studies of the underlying genetic causes of essential hypertension. Except for the genes that cause rare Mendelian forms of hypertension, such as glucocorticoid remediable aldosteronism (chimeric duplication of 11 beta-hydroxylase and aldosterone synthase) (3), and Liddle's Syndrome ( $\beta$ and $\gamma$ subunits of renal-epithelial sodium channel) (4), the strongest evidence implicating a gene as the cause of human essential hypertension is for the angiotensinogen (AGT) gene (5). Angiotensinogen is converted to angiotensin-II $(A n g-I I)^{1}$ through the successive actions of renin and angiotensin converting enzyme (ACE). Ang-II is a potent regulator of vascular hemodynamics and a determinant of cardiovascular homeostasis; inhibitors of Ang-II production (ACE inhibitors) or action (Ang-II receptor antagonists) are effective antihypertensive agents in many patients.

Additional evidence supporting a role for $A G T$ in the genetic basis of hypertension comes from studies reporting that: (a) the angiotensinogen gene from the spontaneously hypertensive rat $(\mathrm{SHR})$ cosegregates with pulse pressure in SHR $\times$ Wistar Kyoto $\mathrm{F}_{2}$ intercrosses (6), (b) central administration of $A G T$ antisense oligonucleotides lowers blood pressure in the SHR $(7,8),(c)$ transgenic mice containing both the human renin $(H R E N)$ and human angiotensinogen (HAGT) genes exhibit high plasma Ang-II levels, altered baroreflex activity, and chronic hypertension (9), and $(d)$ plasma angiotensinogen and arterial blood pressure vary proportionally with the number of functional copies of the mouse Agt ( $m A g t)$ gene in gene-targeted mice $(10,11)$. Further interest in the $A G T$ gene stems from studies implicating variants of the gene in the genetic basis of preeclampsia, a disorder characterized by hypertension, proteinuria, and edema after the 20th wk of pregnancy $(12,13)$.

1. Abbreviations used in this paper: $\mathrm{ACE}$, angiotensin converting enzyme; AGT, human angiotensinogen protein; Ang, angiotensin; MAP, mean arterial pressure; RAS: renin-angiotensin system. 
The renin-angiotensin system (RAS) may also play an important role in regulating growth and development of several organs. Agt-/- mice exhibit hypotension and reduced survival by weaning (3 wk of age) (11). An analysis of both preweanling $A g t-/-$ mice and occasional adult survivors has demonstrated marked renal abnormalities consisting of severe renal vascular hypertrophy, cortical thinning, severe focal fibrosis, tubular atrophy, and chronic inflammation $(11,14,15)$.

We have developed transgenic mice containing the HREN and $H A G T$ genes as tools for studying the regulation of the human RAS and its role in blood pressure regulation and organ function. Driven by their respective endogenous promoters, each of these transgenes exhibits normal tissue- and cellspecific expression and are appropriately regulated (16-19). Although the enzymatic reaction between renin and angiotensinogen is species specific (i.e., human renin cannot cleave mouse angiotensinogen, and mouse renin cannot cleave human angiotensinogen), the Ang-I and Ang-II peptides are identical in rodents and humans (20). We therefore proposed that elements of the human RAS may be able to complement the lethal phenotype observed in mice homozygous for a targeted disruption of the $m A g t$ gene. The aim of this study was to transfer the $H R E N$ and $H A G T$ transgenes into $m A g t$-deficient mice in order to determine whether those elements of the human RAS would rescue the reduced survival and correct the renal and cardiovascular abnormalities observed in $m A g t$-deficient mice. The resulting mice should also provide a model to further study the regulation of the HREN and $H A G T$ genes without the confounding influence of their endogenous counterparts, and to assess the feasibility of examining the physiological significance of $H A G T$ variants identified in human molecular genetic studies using a combined transgenic and gene-targeting approach.

\section{Methods}

Experimental mice and husbandry. The generation of mice having a targeted disruption of the $m A g t$ gene has been described previously (11); the $m A g t+/-$ mice used for the breeding scheme illustrated in Fig. 1 were maintained by backcross breeding to C57BL/6J. The methods used for the generation of mice containing both the HREN and $H A G T$ transgenes have been described previously $(9,16,18)$. In addition, the tissue- and cell-specific expression exhibited by both

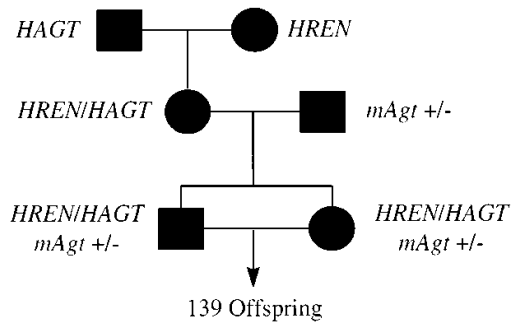

Figure 1. Breeding scheme. A schematic of the breeding strategy used to generate mice containing combinations of the $H R E N$ and $H A G T$ transgenes and gene-targeted disruptions of the $m A g t$ gene. Male mice are repre-

sented by a square, and females by a circle. Brother/sister intercrosses of double transgenic $\mathrm{mAgt}+/$ - mice yielded 139 offspring that were analyzed for genotypes. A subset of each genotypic group was analyzed for blood pressures and kidney histologies. The individual $H R E N$ and HAGT transgenics used to generate the double transgenic mice in the first breeding are heterozygous for each of the transgenes. The $H R E N$ transgene is present on the $\mathrm{X}$-chromosome and exhibits a sex-linked mode of inheritance. The HAGT gene is autosomal. transgenes in single and double transgenic mice has been previously described in detail $(9,16-18)$. The HAGT transgene segregates as an autosomal trait while the HREN transgene is linked to the X-chromosome $(16,18)$.

Pups were weaned at $21 \mathrm{~d}$, at which time tail biopsies were taken for genotyping. To assess the relative survival of pups of the various genotypes, all cages were monitored carefully from birth for dead mice, which were retrieved for sampling and genotyping. After weaning, cages continued to be monitored carefully for deaths. All mice were fed standard mouse chow (LM-485; Teklad Premier Laboratory Diets, Madison, WI) and water ad libitum. Care of the mice used in the experiments met or exceeded the standards set forth by the National Institutes of Health in their Guidelines for the Care and Use of Experimental Animals. All procedures were approved by the University Animal Care and Use Committee at the University of Iowa.

Genotyping. Genomic DNA was purified from tail biopsy samples as previously described $(21,22)$. The $m A g t$ locus was genotyped by Southern blot analysis as previously described (11). Briefly, XbaIdigested tail DNA was separated on $0.8 \%$ agarose gels, transferred to nitrocellulose membranes, and hybridized with a radioactively labeled DNA probe that spans the area of the targeted disruption, exon 2. HREN and $H A G T$ oligonucleotide primer sets specific for human sequences were used to assay for the presence or absence of the transgenes as described previously (9). This PCR-based assay does not allow us to distinguish between mice that are either heterozygous or homozygous for the HREN or HAGT transgenes. Since the level of plasma human angiotensinogen is already in high excess, it is unlikely that the presence of additional copies of the transgene will have any effects on the blood pressure of those mice (18). Moreover, since the HREN gene is linked to the X-chromosome $(16,17)$, all HREN transgenic males will be hemizygous for the transgene. Although female mice may differ with respect to the HREN transgene copy number, the absence of a difference in blood pressure between males and females in any experimental group, the low variance in blood pressure measurements within individual groups and the high correlation between $m A g t$ gene copy number in the $\mathrm{RA}^{+}$group (see Results), argues against a transgene copy number effect on blood pressure.

Blood pressure measurement. $3 \mathrm{~d}$ before blood pressure recording, mice were weighed, anesthetized with ketamine $(120 \mathrm{mg} / \mathrm{kg}$, i.p.) and acepromazine maleate $(12 \mathrm{mg} / \mathrm{kg}$, i.p.), and surgically instrumented with a left common carotid artery catheter (Microrenathane; Braintree Science Inc., Braintree, MA) (0.04 in outer diameter $\times$ 0.025 in inner diameter, drawn over heat) for the measurement of pulsatile and mean arterial blood pressure (MAP) and heart rate (HR, pulse pressure-triggered cardiotachometer). The catheter was tunneled subcutaneously, exteriorized between the scapulae, and the free end was led through a larger piece of protective tubing (PE 160) that was flanged at one end. The scapular incision was closed around the flanged end of the tubing to secure the catheter to this region. The neck wounds were also closed (silk 6-0). Catheters were filled and flushed daily with a sterile dilute heparinized saline $(25 \mathrm{U} / \mathrm{ml})$. After a 3-d recovery period, mice remained in their home cages and were connected to a Beckman Dynograph-coupled pressure transducer (Cobe Laboratories, Inc., Lakewood, CO) for the recording of cardiovascular parameters. The mice were allowed a 60-min stabilization period after connection to the recording equipment. Mice were allowed to move freely. Blood pressure and HR were recorded continuously for 90-120 min and the data was calculated from the mean of five MAP and HR samplings for each animal during this time.

Organ collection and renal histology. After blood pressure recording, mice were killed by $\mathrm{CO}_{2}$ asphyxiation. A midline abdominal incision was made and the kidneys were removed, rinsed in sterile saline, and fixed in $10 \%$ neutral-buffered formalin. The kidneys were embedded in paraffin, sectioned (5 $\mu \mathrm{m}$ coronal and saggital), and stained with hematoxylin and eosin. Arterial wall thickness, cortical thickness, number and size of cortical tubules, presence of interstitial inflammatory cells, and glomerular density were examined in the kidneys of a minimum of two different mice from each of the genotype 
groups: $\mathrm{RA}^{-} m A g t-1-, \mathrm{RA}^{+} m A g t-1-, \mathrm{RA}^{-} m A g t+1+, \mathrm{RA}^{+}$ $m A g t+/+$, and $\mathrm{RA}^{-} m A g t+/-$. Investigators examining the histological samples were "blind" to the genotypes.

Statistical analysis. Blood pressure is expressed as mean \pm SEM. The SEM was determined by the formula (EMS $/ n)^{1 / 2}$ where EMS is the error mean square term from ANOVA and $n$ is the number of animals per group (23). The data were analyzed by one-way ANOVA (23) followed by Student's modified $t$ test with Bonferroni correction for multiple comparisons between means (24) using the modified error mean square term from the ANOVA. Genotype frequencies were compared with expected Mendelian proportions by chi-square $\left(\chi^{2}\right)$ (25). Regression analysis was used to determine the relationship between $m A g t$ gene copy number and MAP (26).

\section{Results}

Experimental strategy. The long term goal of the studies of which the present experiments are a part is to develop animal models to examine the physiological importance of candidate $A G T$ gene variants reported to be associated with increased plasma angiotensinogen and high blood pressure in humans (5, 13). We here use a combination of transgenic and gene-targeting techniques to functionally replace the mouse renin-angiotensin system with its human equivalent. We have previously demonstrated that transgenic mice containing the HREN and $H A G T$ genes express the human genes appropriately (16-18) and that their combined expression results in chronic hypertension (9). We have also observed that the expression of endogenous renin mRNA was modulated in the hypertensive mice in response to increased blood pressure and/or Ang-II levels (19). We therefore wanted to determine if the HREN and $H A G T$ genes could functionally replace the endogenous mouse renin and angiotensinogen genes in order to ensure that any subtle effects on blood pressure of subsequent $H A G T$ gene variants would not be masked by compensatory changes in the endogenous system. Gene-targeted mice deficient in $m$ Agt $(11,14,15), \operatorname{ACE}(27,28)$, Ang-II type 1 A receptor (29, $30)$, and Ang-II type II receptor $(31,32)$ have been developed. We chose the $A g t$ deficient mice because the angiotensinogen protein (AGT) provides the only known Ang-II precursor and that its deletion should functionally cripple the system. This would allow the mouse ACE and Ang-II receptors to become dependent upon HREN and HAGT and function as a human/ mouse chimeric RAS.

Breeding and genotyping. Fig. 1 shows the breeding scheme used to generate transgenic mice containing both the HREN and $H A G T$ genes on $m A g t-/-$ background. In the first round of breeding, heterozygous male $H A G T$ mice $\left(\mathrm{A}^{+} / \mathrm{A}^{-}\right)$were bred with heterozygous female $H R E N$ mice $\left(\mathrm{R}^{+} / \mathrm{R}^{-}\right)$and the double transgenics $\left(\mathrm{R}^{+} / \mathrm{A}^{+}\right)$were identified by PCR and selected for further breeding. In the second generation, male $m A g t+/$ - mice were bred with female double transgenic mice from the first breeding. Brother and sister offspring containing both human transgenes, as identified by PCR, and also heterozygous for the $m A g t$ deletion, as identified by Southern blot analysis, were interbred for the third round of breeding. This strategy yielded offspring with different combinations of the human transgenes and targeted $m A g t$ alleles that were distinguished by PCR and Southern blot analysis as illustrated in Fig. 2. Our previous data showed that single transgenic mice $\left(\mathrm{R}^{+} / \mathrm{A}^{-}, \mathrm{R}^{-} / \mathrm{A}^{+}\right)$are phenotypically indistinguishable from nontransgenic mice $\left(\mathrm{R}^{-} / \mathrm{A}^{-}\right)$with respect to plasma renin activity, plasma Ang-II levels, and blood pressure (9). Consequently, there are only two combinations of $H R E N / H A G T$ transgenes that need to be distinguished: double transgenic animals having both HREN and HAGT transgenes, which we will designate $\mathrm{RA}^{+}$, and animals having no or one transgene, which we will designate $\mathrm{RA}^{-}$. Thus, when combined with three possible $m A g t$ genotypes, there are six classes of animals.

Genotype data were collected on 139 live born offspring (71 males and 68 females) from 19 litters of the $\mathrm{R}^{+} / \mathrm{A}^{+} m A g t+/-$ intercross. Each mouse was scored as either positive or negative for each human transgene and either as wild type $(+/+)$, heterozygous $(+/-)$, or homozygous $(-/-)$ for the gene-targeted deletion at the $m A g t$ locus. A summary of all genotype data from this population is shown in Table I.

Complementation of the lethal phenotype. The breeding strategy we employed yielded a large number of double transgenic mice $\left(\mathrm{RA}^{+}, n=69\right)$. We were therefore able to obtain a sub-

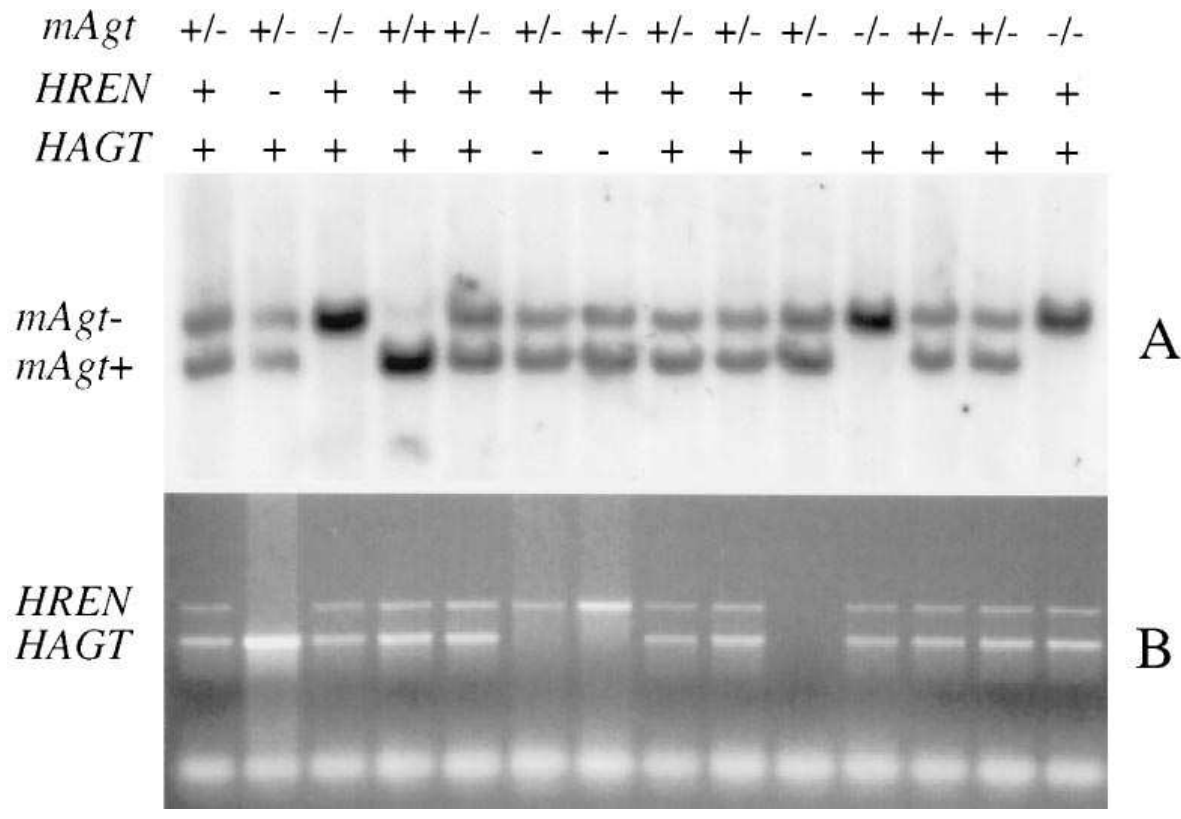

Figure 2. Sample genotype data. (A) A representative Southern blot of Xba1digested tail DNA from offspring of the breeding shown in Fig. 1 is shown. Hybridizing bands corresponding to the wildtype $(m A g t+)$ and targeted $(m A g t-)$ loci are indicated. $(B)$ A representative gel of tail DNA PCR reactions using primers specific for the HREN and HAGT genes is shown. Positions of the PCR products are indicated. + , transgene positive; - , transgene negative. The deduced genotype for each animal is shown at the top of each lane. 
Table I. Genotype Summary from all Offspring

\begin{tabular}{lrrrr}
\hline & \multicolumn{4}{c}{ HREN/HAGT genotype } \\
\cline { 2 - 5 } mAgt genotype & $\mathrm{R}^{-} / \mathrm{A}^{-}$ & $\mathrm{R}^{+} / \mathrm{A}^{-}$ & $\mathrm{R}^{-} / \mathrm{A}^{+}$ & $\mathrm{R}^{+} / \mathrm{A}^{+}$ \\
\hline$+/+$ & 4 & 10 & 5 & 18 \\
$+/-$ & 17 & 19 & 5 & 34 \\
$-/-$ & 4 & 5 & 1 & 17 \\
\hline
\end{tabular}

stantial number of animals in which survival could be correlated with RA and $m A g t$ genotypes. A summary of the $m A g t$ locus genotype in the two populations, $\mathrm{RA}^{+}$(double transgenics) and $\mathrm{RA}^{-}$(nontransgenic or single transgenic), that survived to 3 mo of age is shown in Table II.

The highest mortality rate $(70 \%$ at 3 mo of age and $80 \%$ at 5 mo of age) was evident in $m A g t-/-$ mice that lacked one or both human transgenes $\left(\mathrm{RA}^{-}\right)$. The loss of $\mathrm{RA}^{-} m A g t-/-$ mice was highly significant $\left(P<0.001\right.$ by $\left.\chi^{2}\right)$. Of a total of 131 offspring (139 minus 8 deaths), only three $\mathrm{RA}^{-} m A g t-/-$ mice survived postweaning and only two survived beyond five mo of age. In contrast, in the $\mathrm{RA}^{+}$group we observed the appropriate proportions of animals that were wild type, heterozygous, and homozygous at the $m A g t$ locus as predicted by Mendelian segregation $\left(P>0.05\right.$ by $\left.\chi^{2}\right)$. Indeed, all $\mathrm{RA}^{+}$ $m A g t-1-$ mice (17 total, 9 males and 8 females) survived until they were killed after blood pressure was recorded (5-9 mo of age). Similarly, no significant difference in survival was evident
Table II. Genotype Frequencies of 3-mo Survivors Stratified for HREN/HAGT Genotype

\begin{tabular}{|c|c|c|c|c|c|c|}
\hline \multirow{2}{*}{$\begin{array}{l}H R E N / H A G T \rightarrow \\
m A g t \\
\quad \downarrow\end{array}$} & \multicolumn{3}{|c|}{$\mathrm{RA}^{+}(n=68)$} & \multicolumn{3}{|c|}{$\mathrm{RA}^{-}(n=63)$} \\
\hline & Expected & Observed & Percent & Expected & Observed & Percent \\
\hline$+/+$ & 17 & 17 & 25 & 16 & 19 & 30 \\
\hline$+1-$ & 34 & 34 & 50 & 31 & 41 & 65 \\
\hline$-1-$ & 17 & 17 & 25 & 16 & $3^{*}$ & $5^{*}$ \\
\hline
\end{tabular}

$* P<0.05$ by $\chi^{2}$ for observed vs. expected.

among $m A g t+/+$ or $m A g t+/-$ mice, regardless of the human transgene genotypes. These data clearly demonstrate that the presence of both human transgenes is necessary and sufficient to rescue the lethality caused by the $m A g t$ deletion.

To determine whether homozygous $m A g t-1-$ animals were born at appropriate Mendelian proportions or were dying in utero, we performed two test breedings between $\mathrm{RA}^{-}$ $m A g t+/-$ mice. Offspring were continuously observed over a 3-wk period to ensure collection of their remains after animals died. From a total of 16 offspring, 3 were $m A g t+/+, 7$ were $m A g t+/-$, and 6 were $m A g t-l-$ (3:7:6 vs. $4: 8: 4, P>0.05$ by $\left.\chi^{2}\right)$. However, all the $m A g t-1-$ mice died before weaning, while all remaining mice survived to adulthood.

Complementation of renal pathology. Examination of kidneys from the two surviving adult $\mathrm{RA}^{-} m A g t-/-$ mice
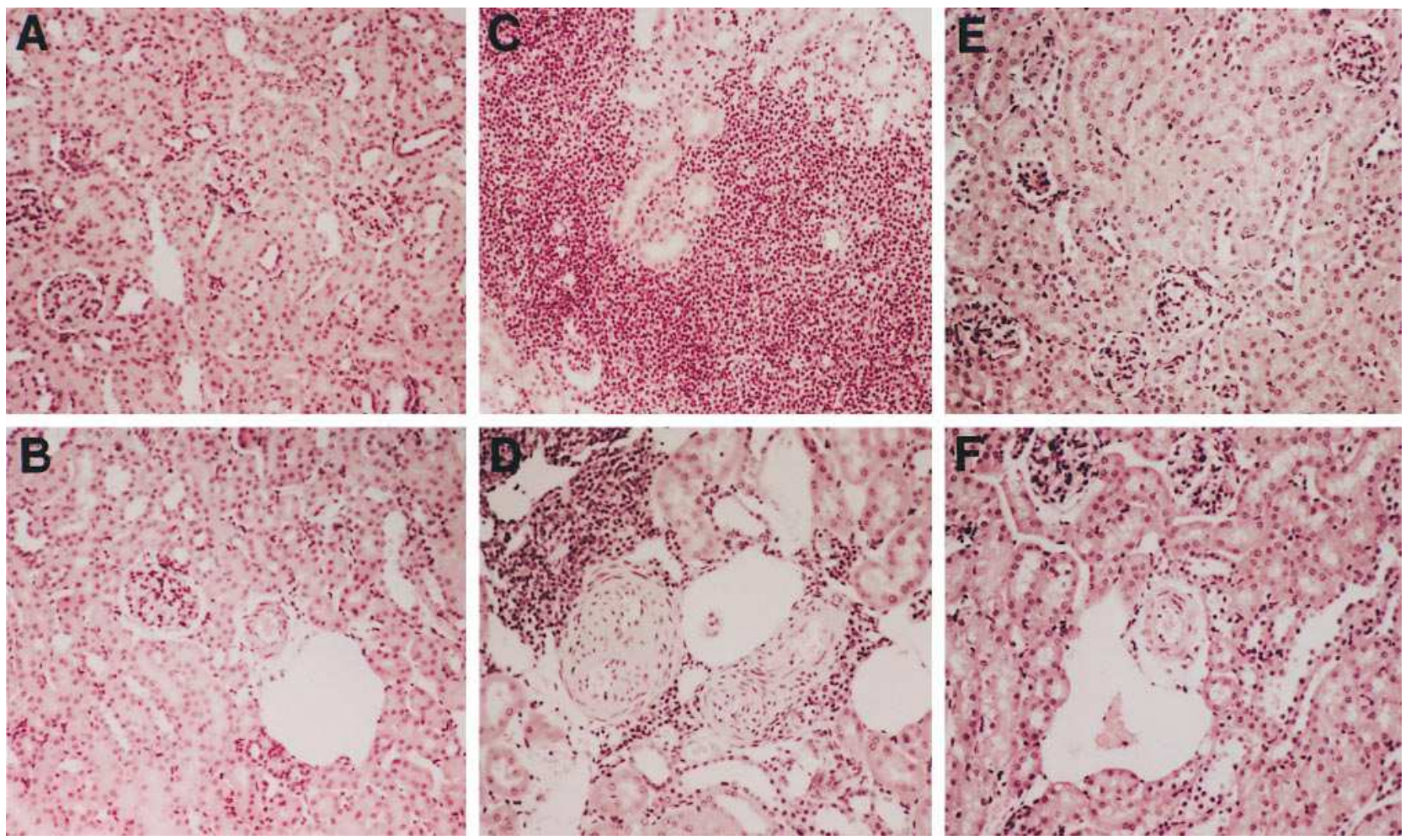

Figure 3. Kidney histopathology. Representative examples of histology of kidneys from an adult wild type $(A$ and $B)$, an $\mathrm{RA}^{-} m A g t-l-(C$ and $D)$, and an $\mathrm{RA}^{+} m A g t-/-(E$ and $F) . A, C$, and $E$ are of the renal cortex. Severe lymphocytic infiltration is evident in a $m A g t-l-$ mouse $(C)$ but not in an $\mathrm{RA}^{+} m A g t-/-$ mouse $(E) . B, D$, and $F$ show a comparison of interlobular arteries. Marked arterial wall thickening is evident in the $m A g t-/-$ mouse $(D)$, but normal arterial wall thickness is evident in the wild type $(B)$ and $\mathrm{RA}^{+} m A g t-l-(F)$. 
showed marked renal pathology. Although not significantly reduced in weight, kidneys from these mutants had thinned cortices surrounding severely atrophied medullary regions. Moderate to severe medial thickening of arterial walls in the $\mathrm{RA}^{-} m A g t-/-$ mice, with near complete occlusion of the lumen in many of the arteries (Fig. $3 D$ ), was observed routinely. Similar dysplasia was evident in the kidneys from $\mathrm{RA}^{-}$ $m A g t-/-$ mice found dead in their cages. In addition to the arterial thickening and occlusion, renal lesions characterized by areas of abnormal parenchyma consisting of numerous cystic spaces around glomeruli, dilated and/or atrophied tubules, and multiple areas of fibrosis often associated with dense lymphocytic infiltrates were commonly observed (Fig. $3 C$ ). The numbers and size of glomeruli were generally reduced compared with kidneys from wild-type controls, although glomeruli outside the hypoplastic zone were frequently enlarged and more cellular. In contrast, kidneys from the $\mathrm{RA}^{+} m A g t-/-$ mice (Fig. 3, $E$ and $F)(n=7)$ were generally indistinguishable from wild-type controls (Fig. 3, $A$ and $B$ ), although some very mild and rare focal regions of fibrosis were detected. In addition, some of the larger arteries in one $\mathrm{RA}^{+}$mouse had mild thickening of the media. Glomeruli, tubules, and the interstitium appeared normal in these mice. There were no abnormalities observed in kidneys from $\mathrm{RA}^{-} m A g t+/-$ or $\mathrm{RA}^{+} m A g t+/-$ mice. Consistent with severe hypertension, the $\mathrm{RA}^{+} m A g t+/+$ mice exhibited thrombotic glomeruli, vascular necrosis, and arteritis.

Physiological characterization of the mice. Blood pressure was measured in representatives of each genotypic group using an indwelling carotid arterial catheter in mice that were conscious and freely moving. A typical pulse pressure tracing and a summary of MAP in each group is shown in Fig. 4. As we
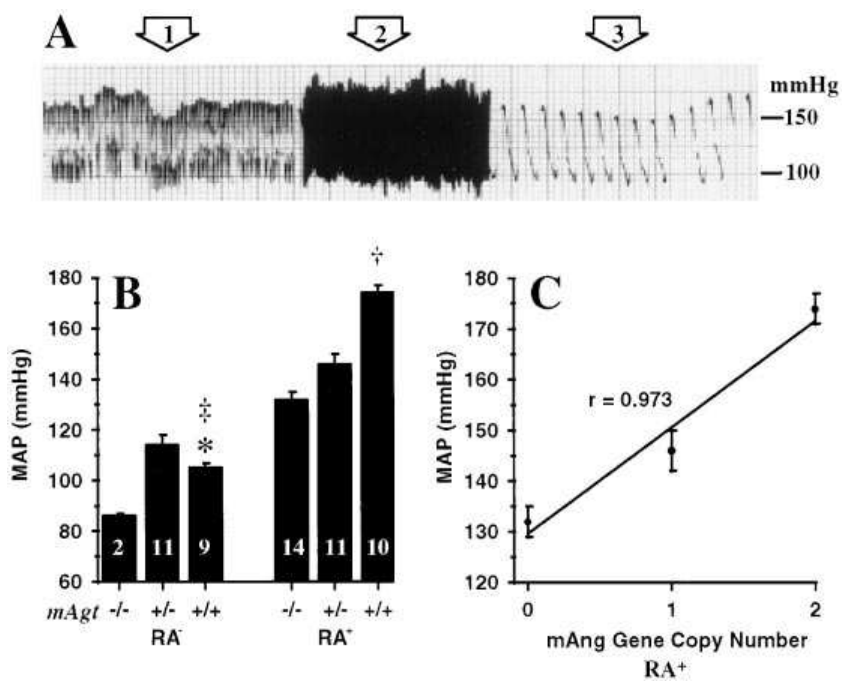

Figure 4. Blood pressure analysis. (A) A typical blood pressure recording in a $26 \mathrm{~g}$ conscious freely moving mouse using a carotid arterial catheter. Arrows 1,2 , and 3 denote chart recorder speeds 0.5 , 0.025 , and $2.5 \mathrm{~mm} / \mathrm{s}$, respectively. (B) A summary of basal MAP in each group of mice. The genotype of each group is shown. Numbers of animals in each group are shown on the bars. Data are expressed as mean \pm SEM. ${ }^{*} P<0.05, \mathrm{RA}^{-} m A g t+/+$ vs. all $\mathrm{RA}^{+}$groups, oneway ANOVA; ${ }^{\ddagger} P<0.05 \mathrm{RA}^{-} m A g t+1+$ vs. $\mathrm{RA}^{-} m A g t-1-$, twosample $t$ test; ${ }^{\dagger} P<0.05, \mathrm{RA}^{+} m A g t+/+$ vs. all other groups. $(C)$ The relationship between MAP and $m A g t$ gene copy number in the $\mathrm{RA}^{+}$ group is shown $(r=0.973, P<0.001)$. have previously demonstrated (9), $\mathrm{RA}^{+} m A g t+/+$ mice are chronically hypertensive $(174 \pm 3 \mathrm{mmHg})$ compared with either single- or nontransgenic control mice $(105 \pm 2 \mathrm{mmHg})$. Both $\mathrm{RA}^{+} m A g t-/-(132 \pm 3 \mathrm{mmHg})$ and $\mathrm{RA}^{+} m A g t+/-$ $(146 \pm 4 \mathrm{mmHg})$ mice had blood pressures that were intermediate between $\mathrm{RA}^{-} m A g t+/+$ and $\mathrm{RA}^{+} m A g t+/+$ animals. There was a strong relationship between $m A g t$ copy number and blood pressure in the $\mathrm{RA}^{+}$population $(r=0.973, P<$ 0.001 , Fig. $4 C$ ). In contrast, two surviving $\mathrm{RA}^{-} m A g t-/-$ adult mice were hypotensive $(86 \pm 1 \mathrm{mmHg})$ compared with wild-type controls $(105 \pm 2 \mathrm{mmHg}$ ) (two-sample $t$ test, $P<$ 0.05). Heart rate did not differ among groups (data not shown, $P>0.05$ for all comparisons), and there was no correlation between blood pressure and the age or sex of the mice used in these studies $(P>0.05$ for all comparisons in mice 5-8 mo of age).

\section{Discussion}

Experimental strategy and rationale. The molecular genetic evidence that variants of the human $A G T$ gene are linked to hypertension and pregnancy-induced hypertension $(5,12,13)$ motivated our long term goal of developing appropriate model systems for experimentally testing the functional consequences of such alleles. In the present work, we generated mice that were transgenic for both HAGT and HREN, but lacked $m A g t$. This experimental approach is made possible by the strict species specificity of the enzymatic reaction between renin and angiotensinogen, which leaves endogenous mouse renin unable to cleave AGT, together with the evolutionary conservation of the Ang-I and Ang-II peptides, which allows the endogenous ACE and Ang-II receptors to function normally. Therefore, in this system we expected that both $H A G T$ and $H R E N$ would be required to restore Ang-I generation, but that the human homologs of the $A C E$ and Ang-II receptor genes would not be necessary. We have previously demonstrated that the HAGT and HREN genes are each expressed in an appropriate tissue- and cell-specific manner (16-18) and that both genes are expressed in double transgenic mice (9). These expectations are validated by our demonstration that a chimeric human/mouse RAS is functional as judged by our finding that transfer of the $H R E N$ and $H A G T$ genes corrects the reduced survival and renal lesions observed in $m A g t-1-$ mice.

The renin-angiotensin system in development. The finding that $A g t$-deficient mice exhibit severe renal lesions shortly after birth suggests that the RAS may play a critical role in the continued development of the kidney during neonatal life. The kidney is among several tissues in which all components of the RAS cascade are expressed (33). Therefore, in addition to the local hemodynamic and volume homeostatic effects regulated by the intrarenal RAS, it remains possible that the system may also be an important regulator of kidney growth and development. The potent effects of ACE inhibitors on regression of ventricular hypertrophy, aortic medial thickness, and myocardial infarction-induced remodeling (34), along with in vitro evidence that Ang-II activates factors associated with growth in a variety of cardiovascular cell types including cardiac myocytes (35), endothelial cells (36), and vascular smooth muscle cells (37) all point to a potential role of the RAS in regulating cardiovascular cell structure and growth. Similarly, pharmacological studies showing that AT-1 receptor blockade (38) or ACE inhibition (39) in neonates results in a reduction in the number and size of renal afferent arterioles and glomeruli has led to 
proposals that the RAS mediates normal embryonic and postnatal kidney development. However, the finding of severe arterial wall thickening and hyperplasia in the kidneys of $m A g t-/-$ mice is unexpected given that Ang-II is a growthpromoting factor. One possible explanation is that absence of AGT and therefore Ang-II may lead to activation of some other growth factors. Indeed, Niimura et al. (14) report an upregulation of platelet-derived growth factor and transforming growth factor mRNA in thickened arteries of $m A g t$-deficient mice. Moreover, recent studies suggesting a role of Ang-II type 2 receptors (AT-2) in apoptosis suggests that the thickened arterial walls could be in part mediated by inappropriate smooth muscle cell replication (40). Because the renal phenotype was not improved in $m A g t-/-$ mice bearing the $H A G T$ gene alone, our findings suggest that it is the loss of Ang-II, rather than AGT per se, that is causal to the renal pathology observed in the $m A g t-/-$. Nevertheless, we cannot formally rule out that des-angiotensin (angiotensinogen without the Ang-II peptide) mediates these effects by an undiscovered mechanism. The need for further studies to delineate the precise mechanisms by which Ang-II participates in growth and development of the kidney is underscored by the finding of an essentially identical form of abnormal renal morphology in ACE-deficient mice (27), but not in AT-1A or AT-2 receptordeficient mice $(29,31)$.

Genotypic variation in blood pressure and implications for future studies. Jeunemaitre et al. (5) found that variants in the $A G T$ gene correlated with small but significant changes in plasma AGT and elevated blood pressure. To determine whether modest increases and decreases in plasma AGT alter blood pressure, Smithies and Kim (10) studied the effects of stepwise increases in the $m A g t$ gene copy number from one to four and found a significant increase in both plasma AGT (from $35 \%$ of normal in one-copy mice to $145 \%$ of normal in four-copy mice) and blood pressure $(\sim 8 \mathrm{mmHg}$ per gene copy). Our studies also demonstrate that blood pressure in the double transgenic mice is proportional to $m A g t$ gene copy number. Surprisingly, the effect is considerably greater $(\sim 21$ mmHg per $m A g t$ copy) in the double transgenics. These data show that the hypertension observed in the double transgenics that are wild type at the $m A g t$ locus is due to the additive effect of the endogenous and the human renin-angiotensinogen genes. The contribution of the human genes is quantitatively greater than the contribution of the mouse genes in this model since blood pressure in $\mathrm{RA}^{+} m A g t+/+$ is $\sim 42 \mathrm{mmHg}$ higher than $\mathrm{RA}^{+} m A g t-/-$ mice, but $69 \mathrm{mmHg}$ higher than $\mathrm{RA}^{-}$ $m A g t+/+$.

The proportionality of $m A g t$ copy number and blood pressure in the $\mathrm{RA}^{+}$mice was initially surprising since we previously reported that mouse renin mRNA is downregulated in the kidney of the double transgenics (19). In normal mice, however, plasma renin is high whereas plasma AGT is low (41, 42). Evidently, even when renin mRNA is significantly downregulated, sufficient plasma renin remains so that as plasma AGT increases with increasing $m A g t$ gene copy number, mAgt-derived Ang-II in excess of that produced from human AGT causes an increase in blood pressure. The surprisingly large effect may indicate that the homeostatic mechanisms in the $\mathrm{RA}^{+}$mice are stressed to the point that compensation for variations in $\mathrm{mAGT}$ levels are less effective than in $\mathrm{RA}^{-}$mice.

We expect that the use of a combined transgenic/gene-targeted mouse strategy of the type illustrated here will allow us to functionally examine the role of human $A G T$ variants in causing hypertension. The above data emphasize the value of using $m A g t-/-$ mice for determining the contribution of human RAS gene variants to blood pressure differences, since in these animals homeostatic changes in mouse renin synthesis will not affect Ang-II levels. This avoids many of the complications that altered mouse RAS activity can introduce when comparing the blood pressure in animals containing a series of variants. We are therefore using a novel gene targeting approach to transfer various haplotypes of the $H A G T$ gene to a selectable locus where single-copy identical-site insertions can be accomplished (43). This will eliminate copy-number and position effects on expression that result from random integration of transgenes into the genome (43-46) and consequently will allow us to make a direct comparison of blood pressure in mice containing different allelic variants. Once these gene-targeted transgenics are generated, we will make use of preexisting HREN transgenics and $m A g t$-deficient mice as described in this report to test the functional significance of genetic variants of the $H A G T$ gene.

\section{Acknowledgments}

We thank Kathy Walters, Julie Lang, Norma Sinclair, and Lucy Robbins for their superb technical assistance, and Drs. Stephen J. Lewis and David C. Merrill for their expertise, equipment, and advice.

Funds to support this project were provided by the National Institutes of Health (NIH) (HL-48058 and HL-55006 to C.D. Sigmund, HL-49277 and GM-20069 to O. Smithies, and HL-03470 to J.H. Krege), and Baxter Healthcare Corporation (to C.D. Sigmund). C.D. Sigmund is an Established Investigator of the American Heart Association. R.L. Davisson is funded by an NIH Postdoctoral National Research Service Award (F32 HL-09590). J.H. Krege was a Howard Hughes Postdoctoral Fellow. Transgenic mice were generated and maintained at the University of Iowa Transgenic Animal Facility, which is supported in part by the College of Medicine and the Diabetes and Endocrinology Research Center. Histology was performed in the Electron Microscopy Core Facility.

\section{References}

1. Ward, R. 1990. Familial aggregation and genetic epidemiology of blood pressure. In Hypertension: Pathophysiology, Diagnosis and Management. J.H. Laragh and B.M. Brenner, editors. Raven Press, New York. 81-100.

2. Lifton, R.P., P.N. Hopkins, R.R. Williams, N.K. Hollenberg, G.H. Williams, and R.G. Dluhy. 1989. Evidence for heritability of non-modulating essential hypertension. Hypertension (Dallas). 13:884-889.

3. Lifton, R.P., R.G. Dluhy, M. Powers, G.M. Rich, S. Cook, S. Ulick, and J.M. Lalouel. 1992. A chimaeric 11 beta-hydroxylase/aldosterone synthase gene causes glucocorticoid-remediable aldosteronism and human hypertension. $\mathrm{Na}$ ture (Lond.). 355:262-265.

4. Shimkets, R.A., D.G. Warnock, C.M. Bositis, C. Nelson-Williams, J.H. Hansson, M. Schambelan, J.R. Gill, S. Ulick, R.V. Milora, J.W. Findling, et al. 1994. Liddle's syndrome: heritable human hypertension caused by mutations in the b subunit of the epithelial sodium channel. Cell. 79:407-414.

5. Jeunemaitre, X., F. Soubrier, Y.V. Kotelevtsev, R.P. Lifton, C.S. Williams, A. Charru, S.C. Hunt, P.N. Hopkins, R.R. Williams, J. Lalouel, and P. Corvol. 1992. Molecular basis of human hypertension: role of angiotensinogen. Cell. 71:169-180.

6. Lodwick, D., M.A. Kaiser, J. Harris, F. Cumin, M. Vincent, and N.J. Samani. 1995. Analysis of the role of angiotensinogen in spontaneous hypertension. Hypertension (Dallas). 25:1245-1251.

7. Gyurko, R., D. Wielbo, and M.I. Phillips. 1993. Antisense inhibition of $\mathrm{AT}_{1}$ receptor mRNA and angiotensinogen mRNA in the brain of spontaneously hypertensive rats reduces hypertension of neurogenic origin. Regul. Pept. 49:167-174.

8. Wielbo, D., C. Sernia, R. Gyurko, and M.I. Phillips. 1995. Antisense inhibition of hypertension in the spontaneously hypertensive rat. Hypertension (Dallas). 25:314-319.

9. Merrill, D.C., M.W. Thompson, C. Carney, G. Schlager, J.E. Robillard, 
and C.D. Sigmund. 1996. Chronic hypertension and altered baroreflex responses in transgenic mice containing the human renin and human angiotensinogen genes. J. Clin. Invest. 97:1047-1055.

10. Smithies, O., and H.-S. Kim. 1994. Targeted gene duplication and disruption for analyzing quantitative genetic traits in mice. Proc. Natl. Acad. Sci. USA. 91:3612-3615.

11. Kim, H.S., J.H. Krege, K.D. Kluckman, J.R. Hagaman, J.B. Hodgin, C.F. Best, J.C. Jennette, T.M. Coffman, N. Maeda, and O. Smithies. 1995. Genetic control of blood pressure and the angiotensinogen locus. Proc. Natl. Acad. Sci. USA. 92:2735-2739.

12. Ward, K., A. Hata, X. Jeunemaitre, C. Helin, L. Nelson, C. Namikawa, P.F. Farrington, M. Ogasawara, K. Suzumori, S. Tomoda, et al. 1993. A molecular variant of angiotensinogen associated with preeclampsia. Nat. Genet. 4:5961.

13. Inoue, I., A. Rohrwasser, C. Helin, X. Jeunemaitre, P. Crain, J. Bohlender, R.P. Lifton, P. Corvol, K. Ward, and J.-M. Lalouel. 1995. A mutation of angiotensinogen in a patient with preeclampsia leads to altered kinetics of the renin-angiotensin system. J. Biol. Chem. 270:11430-11436.

14. Niimura, F., P.A. Labosky, J. Kakuchi, H. Okubo, T. Yoshida, T. Oikawa, T. Ichiki, A.J. Naftilan, A. Fogo, T. Inagami, et al. 1995. Gene targeting in mice reveals a requirement for angiotensin in the development and maintenance of kidney morphology and growth factor regulation. J. Clin. Invest. 96: 2947-2954.

15. Tanimoto, K., F. Sugiyama, Y. Goto, J. Ishida, E. Takimoto, K. Yagami, A. Fukamizu, and K. Murakami. 1994. Angiotensinogen-deficient mice with hypotension. J. Biol. Chem. 269:31334-31337.

16. Sigmund, C.D., C.A. Jones, C.M. Kane, C. Wu, J.A. Lang, and K.W. Gross. 1992. Regulated tissue- and cell-specific expression of the human renin gene in transgenic mice. Circ. Res. 70:1070-1079.

17. Sigmund, C.D. 1993. Expression of the human renin gene in transgenic mice throughout ontogeny. Pediatr. Nephrol. 7:639-645.

18. Yang, G., D.C. Merrill, M.W. Thompson, J.E. Robillard, and C.D. Sigmund. 1994. Functional expression of the human angiotensinogen gene in transgenic mice. J. Biol. Chem. 269:32497-32502.

19. Thompson, M.W., S.B. Smith, and C.D. Sigmund. 1996. Regulation of human renin mRNA expression and protein release in transgenic mice. Hypertension (Dallas). 28:290-296.

20. Hatae, T., E. Takimoto, K. Murakami, and A. Fukamizu. 1994. Comparative studies on species-specific reactivity between renin and angiotensinogen. Mol. Cell. Biochem. 131:43-47.

21. Sigmund, C.D., C.A. Jones, H. Jacob, J. Ingelfinger, U. Kim, D. Gamble, V.J. Dzau, and K.W. Gross. 1991. Pathophysiology of vascular smooth muscle in renin promoter-T antigen transgenic mice. Am. J. Physiol. 260:F249F257.

22. Hogan, E., F. Costantini, and E. Lacy. 1986. Manipulating the mouse embryo. Cold Spring Harbor Laboratory, Cold Spring Harbor, New York.

23. Winer, B.J. 1971. Statistical principals of experimental design. McGrawHill Book Co., New York. 752 pp.

24. Wallenstein, S., C.L. Zucker, and J.L. Fleiss. 1980. Some statistical methods useful in circulation research. Circ. Res. 47:1-9.

25. Goldstein, A. 1964. Biostatistics: an introductory text. MacMillan Co., New York. 102 pp.

26. Kleinbaum, D.G., L.L. Kupper, and K.E. Muller. 1990. Applied regression analysis and other multivariable methods. PWS Publishing Co., Boston. 80 pp.

27. Krege, J.H., S.W.M. John, L.L. Langenbach, J.B. Hodgin, J.R. Hagaman, E.S. Bachman, J.C. Jennette, D.A. O'Brien, and O. Smithies. 1995. Malefemale differences in fertility and blood pressure in ACE-deficient mice. Nature (Lond.). 375:146-148.

28. Esther, C.R., Jr., T.E. Howard, E.M. Marino, J.M. Goddard, M.R. Capecchi, and K.E. Bernstein. 1996. Mice lacking angiotensin-converting en- zyme have low blood pressure, renal pathology, and reduced male fertility. Lab. Invest. 74:953-965.

29. Ito, M., M.I. Oliverio, P.J. Mannon, C.F. Best, N. Maeda, O. Smithies, and T.M. Coffman. 1995. Regulation of blood pressure by the type 1A angiotensin II receptor gene. Proc. Natl. Acad. Sci. USA. 92:3521-3525.

30. Sugaya, T., S. Nishimatsu, K. Tanimoto, E. Takimoto, T. Yamagishi, K. Imamura, S. Goto, K. Imaizumi, Y. Hisada, A. Otsuka, et al. 1995. Angiotensin II type 1a receptor-deficient mice with hypotension and hyperreninemia. $J$. Biol. Chem. 270:18719-18722.

31. Hein, L., G.S. Barsh, R.E. Pratt, V.J. Dzau, and B.K. Kobilka. 1995. Behavioural and cardiovascular effects of disrupting the angiotensin II type- 2 receptor in mice. Nature (Lond.). 377:744-747.

32. Ichiki, T., P.A. Labosky, C. Shiota, S. Okuyama, Y. Imagawa, A. Fogo, F. Niimura, I. Ichikawa, B.L.M. Hogan, and T. Inagami. 1995. Effects on blood pressure and exploratory behavior of mice lacking angiotensin II type-2 receptor. Nature (Lond.). 377:748-750.

33. Gomez, R.A., A. Tufro-McReddie, V.F. Norwood, M. Harris, and E.S Pentz. 1994. Renin-angiotensin system: kidney growth and development. Exp. Nephrol. 2:130.

34. Re, R.N. 1993. Myocardial hypertrophy, angiotensin and ACE inhibitors. Angiology. 44:875-881.

35. Lokuta, A.J., C. Cooper, S.T. Gaa, H.E. Wang, and J.B. Rogers. 1994. Angiotensin II stimulates the release of phospholipid-derived second messengers through multiple receptor subtypes in heart cells. J. Biol. Chem. 269:48324838 .

36. Chua, C.C., C.A. Diglio, B.B. Siu, and B.H. Chua. 1994. Angiotensin II induces TGF-b1 production in rat heart endothelial cells. Biochim. Biophys. Acta. 1223:141-147.

37. Delafontaine, P. and H. Lou. 1993. Angiotensin II regulates insulin-like growth factor I gene expression in vascular smooth muscle cells. J. Biol. Chem. 268:16866-16870.

38. Tufro-McReddie, A., D.W. Johns, K.M. Geary, H. Dagli, A.D. Everett, R.L. Chevalier, R.M. Carey, and R.A. Gomez. 1994. Angiotensin II type 1 receptor: role in renal growth and gene expression during normal development. Am. J. Physiol. 266:F911-F918.

39. Friberg, P., B. Sundelin, S.O. Bohman, A. Bobik, H. Nilson, A. Wickman, H. Gustafsson, J. Petersen, and M.A. Adams. 1994. Renin-angiotensin system in neonatal rats: induction of renal abnormality in response to ACE inhibition or angiotensin II antagonism. Kidney Int. 45:485-492.

40. Yamada, T., M. Horiuchi, and V.J. Dzau. 1996. Angiotensin II type 2 receptor mediates programmed cell death. Proc. Natl. Acad. Sci. USA. 93:156160.

41. Weaver, D., S. Skinner, L. Walker, and M. Sangster. 1991. Phenotypic inhibition of the renin-angiotensin system, emergence of the Ren-2 gene, and adaptive radiation of mice. Gen. Comp. Endocrinol. 83:306-315.

42. Campbell, W.G.J., F. Ganhem, D.F. Catanzaro, G.D. James, M.F. Camargo, J.H. Laragh, and J.E. Sealey. 1996. Plasma and renal prorenin/renin, renin mRNA and blood pressure in Dahl S and R rats. Hypertension (Dallas). 27: 1121-1133.

43. Bronson, S.K., E.G. Plaehn, K.D. Kluckman, J.R. Hagaman, N. Maeda, and O. Smithies. 1996. Single-copy transgenic mice with chosen-site integration Proc. Natl. Acad. Sci. USA. 93:9067-9072.

44. al Shawi, R., J. Kinnaird, J. Burke, and J.O. Bishop. 1990. Expression of a foreign gene in a line of transgenic mice is modulated by a chromosomal position effect. Mol. Cell. Biol. 10:1192-1198.

45. Clark, A.J., P. Bissinger, D.W. Bullock, S. Damak, R. Wallace, C.B.A. Whitelaw, and F. Yull. 1994. Chromosomal position effects and the modulation of transgene expression. Reprod. Fertil. Dev. 6:589-598.

46. Grosveld, F., G.B. van Assendelft, D.R. Greaves, and G. Kollias. 1987. Position-independent, high-level expression of the human beta-globin gene in transgenic mice. Cell. 51:975-985. 